Review

\title{
Beneficial Effects of Antioxidants in Male Infertility Management: A Narrative Review
}

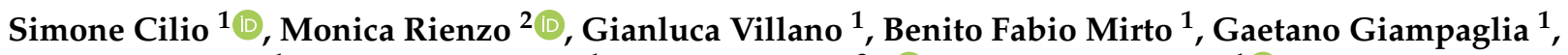 \\ Federico Capone ${ }^{1}$, Gianpiero Ferretti ${ }^{1}$, Erika Di Zazzo ${ }^{3, *}$ (i) and Felice Crocetto ${ }^{1}$ (D)
}

1 Urology Unit, Department of Neurosciences, Reproductive Sciences and Odontostomatology, University of Naples “Federico II", 80138 Napoli, Italy; simocilio.av@gmail.com (S.C.); gianvi195@gmail.com (G.V.); fmirto22@gmail.com (B.F.M.); gaetanogiampaglia@hotmail.it (G.G.); fedecapone@outlook.it (F.C.); gianpi17@hotmail.it (G.F.); felice.crocetto@unina.it (F.C.)

2 Department of Environmental, Biological, and Pharmaceutical Sciences and Technologies, University of Campania "Luigi Vanvitelli", 81100 Caserta, Italy; monica.rienzo@unicampania.it

3 UOC Laboratorio Analisi, Department of Medicine and Health Sciences "V. Tiberio", University of Molise, Ospedale "A. Cardarelli", 86100 Campobasso, Italy

* Correspondence: erika.dizazzo@unimol.it

Citation: Cilio, S.; Rienzo, M.; Villano, G.; Mirto, B.F.; Giampaglia, G.; Capone, F.; Ferretti, G.; Di Zazzo, E.; Crocetto, F. Beneficial Effects of Antioxidants in Male Infertility Management: A Narrative Review. Oxygen 2022, 2,1-11. https:// doi.org/10.3390/oxygen2010001

Academic Editor: John Hancock

Received: 29 December 2021

Accepted: 27 January 2022

Published: 28 January 2022

Publisher's Note: MDPI stays neutral with regard to jurisdictional claims in published maps and institutional affiliations.

Copyright: (C) 2022 by the authors. Licensee MDPI, Basel, Switzerland. This article is an open access article distributed under the terms and conditions of the Creative Commons Attribution (CC BY) license (https:// creativecommons.org/licenses/by/ $4.0 /)$.

\begin{abstract}
Background: Infertility, defined as the failure to conceive after one year of regular, unprotected intercourse, affects 50-80 million people worldwide. A male factor is involved in approximately $20-30 \%$ of cases. In the etiology of male infertility, the association between poor semen quality and oxidative stress (OS) is well known. High levels of reactive oxygen species (ROS) allow the oxidation of DNA, proteins, and lipids of sperm cells, modifying their vitality, motility, and morphology. Methods: To evaluate the effects of antioxidants on sperm in infertile men, we queried the MEDLINE database (via the PubMed interface) for published studies in the last 10 years (2011-2021). The following keywords were used: "infertility" and -"inositol", -“alpha-lipoic acid", -“zinc", - "folate", -"coenzyme Q10", -"selenium", and -"vitamin". Results: Inositol regulates OS levels in sperm cells thanks to its role in mitochondrial reactions and is involved in several processes favoring sperm-oocyte interactions. Alpha-lipoic acid (ALA) reduces ROS damage and improves semen parameters in terms of spermatozoa's motility, morphology, and count. Poor zinc nutrition may be related to low quality of sperm. Supplementation of folate plus zinc has a positive effect on the sperm concentration and morphology. Supplementation with CoQ10 increases sperm concentration, total and progressive motility. Selenium (Se) supplementation improves the overall semen quality and is related to a higher ejaculated volume. Among vitamins, only vitamin B12 shows a positive effect on semen quality; it increases sperm count and motility and reduces sperm DNA damage. Conclusions: In men showing low-quality semen, diet supplementation with antioxidants may improve the sperm quality by alleviating OS-induced sperm damage and enhancing hormone synthesis and spermatozoa concentration, motility, and morphology. Future clinical trials should be focused on the possible association of several antioxidants to take advantage of combined mechanisms of action.
\end{abstract}

Keywords: antioxidant; male infertility; reactive oxygen species; oxidative stress; sperm

\section{Introduction}

Infertility, a male or female reproductive system disease, is defined by the failure to conceive within one year of regular, unprotected sexual intercourse [1].

World Health Organization (WHO) statistics reveal that infertility affects 50-80 million people worldwide, and male factors account for approximately $20-30 \%$ of all infertility cases [2].

According to the International Classification of Diseases, 11th Revision (ICD-11) (Geneva: WHO 2018), male infertility is commonly caused by alterations in semen ejection, absence or low levels of sperm, or sperm morphology and motility alterations [3]. 
Spermatogenesis represents the process by which spermatozoa production occurs. It is composed of spermatocytogenesis (a mitosis where stem-cell spermatogonia produce primary spermatocytes), meiosis (composed by an exchange of genetic material between homologous chromosomes of primary spermatocytes and a reduction division producing haploid spermatids), and spermiogenesis (the final process where spherical spermatids differentiate into mature spermatids, which are released in seminiferous tubules as spermatozoa with fertilization capacity) [4]. The whole process is under the control of the testes' Sertoli cells that facilitate the progression of germ cells to spermatozoa via direct contact [5].

Once produced, spermatozoa are released by the ejaculation process, leading to spermatozoa-oocyte interaction. In the process, called capacitation [6], sperm become motile, are attracted towards the oocyte, bind to it, undergo the acrosome reaction, and finally fuse with the oocyte plasma membrane to create a zygote [7].

One of the most relevant factors in fertility is gamete quality. It is defined as the ability of spermatozoa and oocyte to interact in order to develop a normal embryo [8]. The spermatozoa quality is normally assessed by a spermiogram [9].

In the heterogeneous etiology of male infertility, the association between poor semen quality and oxidative stress (OS) is well known. OS is defined as the result of an imbalance between reactive oxygen species (ROS) and antioxidant defenses [10]. The first evidence on the role of ROS as a potential contributor to male infertility was discovered in the 1940s [11]. Since then, a vast advance in understanding of the effects of ROS on infertility and spermatic functions has been gained [12].

ROS are highly reactive oxygen-containing molecules, including hydroxyl $\left(\mathrm{HO}^{-}\right)$and superoxide $\left(\mathrm{O}_{2}{ }^{-}\right)$free radicals and non-radical molecules, such as hydrogen peroxide $\left(\mathrm{H}_{2} \mathrm{O}_{2}\right)$. ROS are mainly produced via the mitochondrial electron transport chain and by enzymatic reactions involving cyclooxygenases, NADPH oxidases (NOXs), xanthine oxidases, and lipoxygenases, and through the iron-catalyzed Fenton reaction. Finally, ROS are generated after exposure to physical agents, such as ultraviolet rays and heat [13].

Eukaryotic cells benefit from antioxidants, as they tightly regulate ROS levels. Indeed, even though moderate ROS levels are needed during sperm capacitation and fertilization, high ROS levels could lead to spermatozoa damage [14]. Therefore, antioxidants represent a defense mechanism against OS by reacting with and quenching ROS [15]. Based on their activity, antioxidants are classified in two main groups: enzymatic and non-enzymatic antioxidants. Enzymatic antioxidants, such as superoxide dismutases (SODs) and glutathione peroxidase and reductase, convert dangerous oxidative products to hydrogen peroxide $\left(\mathrm{H}_{2} \mathrm{O}_{2}\right)$ and then to water in a multistep process in the presence of cofactors such as zinc, copper, manganese, and iron. Non-enzymatic antioxidants, endogenously produced or consumed from food or supplements, function by interrupting free radical chain reactions.

OS is an important cause of male infertility due to detrimental changes during spermatogenesis, epididymal maturation, and sperm capacitation [12].

Sperm cells are extremely sensitive to damage caused by high ROS levels because of the large amounts of unsaturated fatty acids in their membranes, which are essential for sperm capacitation, acrosome reaction and sperm/oocyte interaction. Oxidative peroxidation of unsaturated fatty acids mediated by ROS represents the main mechanism of ROS-induced sperm damage, leading to infertility [16].

In sperm cells, due to the high concentration of plasma membrane polyunsaturated fatty acids and the lack of cytoplasmic defense mechanisms [17], high levels of ROS can increase OS by triggering the oxidation of sperm cell DNA, proteins, and lipids, and modifying sperm vitality, motility, and morphology [18].

Sperm DNA integrity and chromatin condensation are pivotal for fertilization. Any form of sperm chromatin alteration or DNA damage results in male infertility [19]. Testicular (defective maturation and abortive apoptosis) and post-testicular (OS) modifications are involved in the sperm-DNA-fragmentation etiology.

DNA packaging alterations could affect sperm chromatin decondensation, which would be detrimental to fertility. The chromatin condensation could be modified by several 
factors, such as zinc deficiency and alterations of protamines, proteins replacing histones during spermatozoa maturation [20].

Commonly, DNA fragmentation is a result of ROS-mediated damage. Direct or indirect ROS-mediated damage results in single- or double-strand fragments and abnormal apoptosis. Sperm DNA fragmentation is caused by extrinsic factors (e.g., smoking, heat exposure, chemotherapeutics, and environmental pollutants) and intrinsic factors (e.g., abortive apoptosis, defective germ cell maturation, and OS) [21].

Caspase activation, phosphatidyl serine externalization, mitochondrial membrane potential change, and DNA fragmentation are apoptosis markers detectable in human ejaculated sperm [22]. ROS impact multiple signaling pathways involved in the activation of extrinsic and intrinsic pathways of apoptosis. However, compelling evidence suggests that in the majority of cases ROS apoptosis induction depends on intrinsic pathway activation, which affects the integrity of the mitochondrial permeability transition pores. ROS also trigger apoptosis by inactivating or increasing Bcl-2 anti-apoptotic protein ubiquitination. In addition, the ROS-dependent induction of apoptosis is related to the disruption of mitochondrial membrane potential upon JNK and p38 phosphorylation stimulation ([23] and refs. therein).

The growing interest in ROS-mediated damage is related to the increasingly noticed role of environmental influence on spermatozoa production. Indeed, as showed by Gallo et al. [8], spermatozoa are exposed to several environmental factors able to increase OS induced by ROS.

Currently, the association of several natural antioxidants, such as inositol, alpha-lipoic acid, zinc, folate, coenzyme Q10, selenium, and vitamins, with sperm quality improvement by acting as a defense mechanism against $\mathrm{OS}$ is well documented.

The current narrative review aims to evaluate the updates on the roles and mechanisms of action of the antioxidants most commonly used in nutrition supplementation as a strategy to improve sperm quality.

\section{Materials and Methods}

The MEDLINE database (via the PubMed interface) was queried for studies published in the last 10 years (2011-2021).

The following keywords were used: "infertility" and -"inositol", -"alpha-lipoic acid", -"zinc", - "folate", - "coenzyme Q10", - "selenium", and -"vitamin".

Systematic reviews and in vitro or in vivo trials related to the effects of antioxidants on sperm cells in low-quality human semen were evaluated.

Studies on animals, studies published before 2011, articles not in the English language, and articles that had not been fully published were excluded.

Two investigators (B.F.M. and G.V.) independently evaluated studies suitable for inclusion. The following data were extracted from all qualified studies: authors, year of publication, study design, and results.

\section{Inositols}

In nature, the most abundant form of inositol is myoinositol (myo-Ins). Serum myoIns cannot cross the tight junctions at the testicular level and is therefore transported into cells by a sodium/myo-Ins cotransport protein, whose expression is sensitive to osmolar changes [24]. Consequently, the concentration of myo-Ins in the seminiferous tubule fluid is greater than in the seminal plasma.

In spermatozoa, the main site of action of myo-Ins is the mitochondria, where, by controlling the intracellular $\mathrm{Ca}^{2+}$ levels, it regulates mitochondrial oxidative metabolism and ATP production. Consequently, myo-Ins improves sperm mitochondrial function, enhancing many processes, such as capacitation, acrosome reaction, and regulation of sperm motility [25]. This leads to an improvement of sperm motility in patients with altered sperm parameters [26]. Accordingly, Governini et al., have demonstrated that treatment with myo-Ins results in a significant increase in sperm motility [17]. 
Once ejaculated, spermatozoa undertake several processes in which myo-Ins is involved, such as capacitation, acrosome reaction [27], and sperm-oocyte interactions [28]. Moreover, Calogero et al., have shown that myo-Ins is a safe supplement able to significantly rebalance serum gonadotropin and inhibin B (a serum marker assessing the presence and function of testicular tissue [29]) levels and to increase the percentage of acrosome-reacted spermatozoa, sperm concentration, total count, and progressive motility [27].

In vitro studies showed that myo-Ins exerts a protective effect against abnormal sperm morphology, and improves sperm progressive and total motility by enhancing mitochondrial ATP production $[17,30,31]$.

Taken together, myo-Ins regulates OS levels in sperm cells thanks to its role in mitochondrial reactions, helps to restore some hormones' balance in subfertile men, and is involved in several processes favoring sperm production and sperm-oocyte interactions leading to fertilization.

\section{Alpha-Lipoic Acid}

Alpha-lipoic acid (ALA) acts as the coenzyme for pyruvate dehydrogenase and alphaketoglutarate dehydrogenase in the mitochondria, contributing to ATP production, which is necessary for sperm viability [32]. Inside cells and tissues, ALA is reduced to dihydrolipoic acid (DHLA), which has a higher antioxidant capacity [33]. ALA and DHLA chelate ROS and transition metals to prevent membrane lipid peroxidation and protein damage [34].

In Haghighian et al., ALA supplementation was compared with placebo in a randomized, triple-blind, placebo-controlled clinical trial. The treated group showed significantly increased sperm concentration, sperm count, and sperm total motility after about 3 months of treatment [35].

Taherian et al., evaluated the intracellular OS and the percentage of sperm DNA fragmentation in a group of subfertile men. Both parameters were significantly reduced by an ALA in vitro preparation. This was likely achieved by reduction in ROS production [36].

Accordingly, Di Tucci et al., carried out a systematic review on the effects of ALA supplementation in couples' fertility. Their analysis identified the potential antioxidant effect of ALA in reducing ROS damage, and showed improvement in semen parameters in terms of spermatozoa motility, morphology, and count [37].

The beneficial effects of ALA supplementation have been tested in men undergoing varicocelectomy for subfertility due to varicocele (varicocele has been one of the conditions potentially involved in the genesis of sperm OS [38]). Abbasi et al., performed a triple-blind randomized control trial assessing the effects of ALA vs. placebo treatment for 80 days after the surgery. At the end of the study, ALA treatment after surgical repair of varicocele demonstrated enhanced sperm quality compared to the control [39].

ALA was also tested as cryoprotection agent during the freezing-thawing process that occurs in assisted reproductive techniques (ART). During cryopreservation, sperm is exposed to different changes that may result in incremental OS and may induce some adverse effects due to cryodamage. Asa et al., have demonstrated that an optimal concentration of ALA protects against ROS production and cryodamage. This is reflected in the improvement of sperm motility and viability and by a decrease in DNA damage, and, consequently, apoptosis [40].

\section{Zinc}

Zinc is the most abundant element in human semen, where its concentration is significantly higher than that found in blood. Seminal plasma zinc originates from the prostate gland and reflects the prostatic secretory function [41]. Zinc affects essential physiological processes, such as cellular responses to OS, DNA repair, cell cycle, and apoptosis [42].

Zinc is necessary for testicular development and normal spermatogenesis. It is involved in antioxidant defense, production, storage, secretion, and function of several enzymes which play important roles in meiosis during spermatogenesis and other gameto- 
genesis stages [43]. It affects the stability of sperm chromatin and biological membranes in general, as it influences the fluidity of lipids [44].

Normozoospermics show high zinc levels in seminal plasma, followed by asthenoteratozoospermics, oligoasthenoteratozoospermics, and azoospermics [45].

Colagar et al., demonstrated that poor zinc nutrition may be an important risk factor for low sperm quality and idiopathic male infertility. Routine determination of zinc levels during infertility investigation is therefore recommended [46].

Alsalman et al., carried out a randomized clinical trial comparing the effects of zinc supplementation on seminal plasma in fertile and infertile men. The results showed that zinc supplementation enhanced the semen quality in infertile men. This effect was depicted in terms of spermatogenesis induction, sex organ growth stimulation, activation of $5 \alpha-$ reductase (converting testosterone into the chemically active form), and an increase in zinc-containing enzyme activity, which improved sperm motility [47].

On the other hand, another study on the role of zinc in male fertility declared that, while zinc improves sperm motility and capacitation in vitro, dietary supplementation has not been shown to increase the pregnancy rate in humans [48].

Taken together, it is apparent that further studies in fertile and infertile men are required to determinate the exact beneficial effects and the optimal doses of zinc in male infertility management.

\section{Zinc and Folic Acid}

Folic acid plays a pivotal role in nucleic acid synthesis and amino acid metabolism. It also shows ROS-scavenger properties, making it a potential antioxidant for male subfertility treatment.

No robust results are reported in the current literature to support supplementation with folic acid alone for subfertile men, but it has a certain role in association with zinc. The effect of this association is analyzed in several studies. Zinc plus folic acid increased inhibin B in peripheral blood [49]. Since inhibin B reflects the quality of Sertoli cells, it is a marker of active spermatogenesis in humans [50].

However, Raigani et al., did not show significant improvements in sperm concentration, motility, and morphology after supplementation with folic acid, zinc, or a combination of them [51]. In contrast, a systematic review and meta-analysis by Irani et al., showed that supplementation with folate plus zinc had a statistically significant benefit to sperm concentration, morphology, and serum folate level compared to the placebo. Accordingly, folate supplementation alone did not seem to be more effective than the placebo [52].

\section{Coenzyme Q10}

Coenzyme Q10 (CoQ10) is an essential cofactor for energy production and has high antioxidant properties [53]. It is a component of the mitochondrial respiratory chain which regulates ROS production, thereby protecting the cell membrane against lipid peroxidationinduced damage [54]. For adequate motility, the sperm cells require a high energy viability, which is produced in mitochondria via oxidative phosphorylation. In the mitochondria, CoQ10 neutralizes free radicals produced during the electron transport chain [55]. However, subfertile men show low CoQ10 concentration levels [53].

Low seminal plasma concentrations of CoQ10 have been correlated with impaired sperm parameters, such as motility. Accordingly, evidence revealed that CoQ10 improves sperm count and motility in infertile men [56,57].

Nadjarzadeh et al., carried out a double-blind, randomized clinical trial to assess the role and the effects of CoQ10 supplementation in improving seminal parameters in oligoasthenoteratozoospermic (OAT) men. They found that the semen of most OAT men exhibits increased OS, which impairs semen parameters and leads to the failure of sperm functions. Moreover, seminal plasma analysis confirmed the already known significant direct correlation between CoQ10 levels and sperm motility and morphology. In their study, 
CoQ10 supplementation for at least three months attenuated OS in seminal plasma and improved antioxidant enzyme activity [58].

Accordingly, García-Díaz et al., observed that CoQ10 supplementation for three months significantly increased sperm concentration, total motility, and progressive motility [59].

Thakur et al., found that the seminal concentration of CoQ10, by improving the total antioxidant capacity, was correlated with some of the most important semen parameters, such as sperm concentration, motility, and morphology [60].

The optimal dosage of CoQ10 is still unknown. However, CoQ10 is one of the most promising molecules to treat idiopathic male infertility [53].

\section{Selenium}

Selenium (Se) is incorporated in a large number of proteins, named selenoproteins, involved in several metabolic pathways related to antioxidant defense, redox state regulation, and cancer prevention [61].

During normal spermatogenesis, mitochondrial activity, and capacitation, Se is involved as a cofactor of antioxidative enzymes responsible for the neutralization and prevention of the synthesis of ROS [62]. Among all selenoproteins involved in male reproduction, glutathione peroxidase plays a critical role in many redox reactions. In spermatozoa, it is incorporated into the mitochondrial membrane, counterbalancing the ROS production occurring in the motility process [63].

Moreover, selenoproteins, such as selenoprotein P (SePP), are required for normal spermatogenesis. SePP is highly concentrated in the testis and in seminal fluid, where it plays an important role in the protection of sperm during storage, genital tract passage, and changes until sperm-oocyte interaction. Indeed, seminal plasma SePP concentration is positively correlated with sperm density and the percentage of vital sperm [64].

Mistry et al., showed the effects of daily Se supplementation in improving the overall semen quality, including sperm count, concentration, morphology, and motility [65]. Moreover, Taleby et al., demonstrated that higher selenium intake was associated not only with an improvement in sperm total motility, but also with higher ejaculated volume [66].

However, selenium levels, in both blood and seminal plasma, should be adequately controlled to avoid excess. Se supplementation may not induce therapeutic benefits and may even reduce the general reproductive potential in males by disrupting the optimal degree of ROS necessary for motility and acrosomal reaction [67]. Indeed, studies on fertile men showed that high levels of plasma Se resulted in sperm morphology impairment and motility reduction [68].

Therefore, at appropriate levels of serum Se, sperm morphology is of good quality, but if the recommended value is exceeded, the morphology becomes compromised. Recent findings call for attention to the use of antioxidant supplements with Se megadoses. Future clinical studies are required to find the effective beneficial dose of Se [69].

\section{Vitamins}

\subsection{Vitamin $E$}

Vitamin $\mathrm{E}$ is the primary antioxidant component of the spermatozoa and protects the cell membrane from ROS [70]. Rengaraj and Hong showed that vitamin E deficiency causes abnormal spermatogenesis [71].

Vitamin E has positive effects on testis and sperm functions, but supplemental prescriptions containing vitamin $\mathrm{E}$ have do little to improve overall sperm quality [70].

\subsection{Vitamin C}

Similar to vitamin $\mathrm{E}$, vitamin $\mathrm{C}$ has a potential role as a membrane protector against ROS. In Cyrus et al., vitamin C supplementation did not improve sperm count, but had some beneficial effects on sperm motility and morphology [72]. However, the real effects of 
supplementation with this nutrient are still controversial and not clear yet. Future clinical trials are required to evaluate the role of this vitamin in male infertility [73].

\subsection{Vitamin $B 12$}

Vitamin B12, or cobalamin, is a cofactor in DNA synthesis and in both fatty acid and amino acid metabolism [74]. Vitamin B12 positively influences semen quality by increasing sperm count and sperm motility and by reducing sperm DNA damage [75].

Moreover, as with ALA, this nutrient has also been tested for protecting spermatozoa from cryodamage during the freezing-thawing process that occurs in ART. Its addition to cryopreservation medium improves sperm viability and motility and reduces the DNA fragmentation that occurs in the freezing-thawing process [76].

Taken together, even though other vitamins display antioxidant effects, only vitamin B12 demonstrated a major role in subfertility management with antioxidant supplementation (even if its mechanism of action is still unclear).

\section{About the Combination of Antioxidants}

In the current literature, the potential role of cotreatment of male infertility by using several antioxidants has been analyzed [19,77,78].

According to Bish et al., a combination of antioxidants could be useful in order to exploit their functions in ROS-inactivation and decreasing ROS production due to enzymatic activities. Thus, the authors recommend a diet containing a mix of antioxidants, especially zinc and selenium [79].

Santoro et al., assessed the in vitro and in vivo effects of supplementation with a mixture of antioxidants containing mainly myo-Ins. Antioxidant preparations could have a beneficial role in semen preparation for in vitro fertilization procedures. Moreover, oral supplementation with the nutraceutical mix improves the performance of OAT sperm, without any risks or side effects [80]. Accordingly, Scaruffi et al., showed an increase in fertilization rates by administering a mix of antioxidants to men before semen deposition [81]. However, both studies agree on the need of further studies to enhance the understanding of the effects.

Contrasting data were found in a recent multicenter, double-blind, randomized, placebo-controlled trial, which concluded that combination antioxidant treatment for the male partner does not improve in vivo pregnancy or live birth rates and does not improve semen parameters or DNA integrity in infertile males' spermatozoa [82].

One of the natural sources of a combination of antioxidants is vegetables. Dietary modifications showed potential benefits in improving sperm quality, and the recommendation is to adhere to a healthy dietary pattern rich in plant-based foods, such as a vegetarian diet, the Dietary Approach to Stop Hypertension (DASH) diet, or the Mediterranean diet, alone or in association with antioxidant supplementations $[83,84]$.

Taken together, the peculiar effect of the combination of antioxidants has not yet been clarified. This is due to the poor populations involved in clinical studies and the lack of randomized, placebo-controlled, double-blind clinical trials. Indeed, a retrospective study noted that the antioxidant therapies available currently may not improve sperm function, and the high cost of treatment could lead to poor patient compliance [85].

\section{Conclusions}

The etiology of several diseases, including male infertility, is strictly dependent on OS [86]. Consequently, normal spermatozoa production, function, and vitality requires a balance between ROS and antioxidants.

In men presenting low-quality semen, diet supplementation with antioxidants showed a potential role in improving the overall sperm quality by alleviating OS-induced sperm damage and enhancing hormone synthesis, spermatozoa concentration, motility, and morphology. Future clinical trials should focus on the association of several antioxidants to take advantage of their combined mechanisms of action. 


\begin{abstract}
Author Contributions: Conceptualization, S.C., E.D.Z., M.R. and F.C. (Federico Capone); investigation, S.C., G.V., B.F.M., G.G., G.F.; visualization, M.R.; writing-original draft preparation, S.C., G.V. and B.F.M.; writing-review and editing, S.C., G.V., B.F.M., E.D.Z., M.R. and F.C. (Felice Crocetto); supervision, S.C., E.D.Z. and F.C. (Felice Crocetto). All authors have read and agreed to the published version of the manuscript.
\end{abstract}

Funding: This research did not receive any specific grant from funding agencies in the public, commercial, or not-for-profit sectors.

Conflicts of Interest: The authors declare no conflict of interest.

\title{
References
}

1. Professionals S-O. EAU Guidelines: Male Sexual Dysfunction. Uroweb. Available online: https://uroweb.org/guideline/malesexual-dysfunction/\#3_2 (accessed on 23 March 2021).

2. Infertility. Available online: https://www.who.int/news-room/fact-sheets/detail/infertility (accessed on 23 December 2021).

3. ICD-11. Available online: https://icd.who.int/en (accessed on 23 December 2021).

4. Johnson, L. Efficiency of spermatogenesis. Microsc. Res. Tech. 1995, 32, 385-422. [CrossRef] [PubMed]

5. Griswold, M.D. The central role of Sertoli cells in spermatogenesis. Semin. Cell Dev. Biol. 1998, 9, 411-416. [CrossRef] [PubMed]

6. Puga Molina, L.C.; Luque, G.M.; Balestrini, P.A.; Marín-Briggiler, C.I.; Romarowski, A.; Buffone, M.G. Molecular Basis of Human Sperm Capacitation. Front. Cell Dev. Biol. 2018, 6, 72. [CrossRef] [PubMed]

7. Tosti, E.; Menezo, Y. Gamete activation: Basic knowledge and clinical applications. Hum. Reprod. Updat. 2016, 22, 420-439. [CrossRef]

8. Gallo, A.; Boni, R.; Tosti, E. Gamete quality in a multistressor environment. Environ. Int. 2020, 138, 105627. [CrossRef]

9. WHO Laboratory Manual for the Examination and Processing of Human Semen. Available online: https://www.who.int/ publications-detail-redirect/9789240030787 (accessed on 15 January 2022).

10. Tremellen, K. Oxidative stress and male infertility-A clinical perspective. Hum. Reprod. Updat. 2008, 14, 243-258. [CrossRef]

11. MacLeod, J. The rôle of oxygen in the metabolism and motility of human spermatozoa. Am. J. Physiol. Leg. Content 1943, 138, 512-518. [CrossRef]

12. O'Flaherty, C. Reactive Oxygen Species and Male Fertility. Antioxidants 2020, 9, 287. [CrossRef]

13. Forman, H.J.; Ursini, F.; Maiorino, M. An overview of mechanisms of redox signaling. J. Mol. Cell. Cardiol. 2014, 73, 2-9. [CrossRef]

14. Gallo, A.; Menezo, Y.; Dale, B.; Coppola, G.; Dattilo, M.; Tosti, E.; Boni, R. Metabolic enhancers supporting 1-carbon cycle affect sperm functionality: An in vitro comparative study. Sci. Rep. 2018, 8, 11769. [CrossRef]

15. Sies, H. Strategies of antioxidant defense. Eur. J. Biochem. 1993, 215, 213-219. [CrossRef] [PubMed]

16. Milostić-Srb, A.; Včev, A.; Tandara, M.; Marić, S.; Kuić-Vadlja, V.; Srb, N.; Holik, D. Importance of Zinc Concentration in Seminal Fluid of Men Diagnosed with Infertility. Acta Clin. Croat. 2020, 59, 154-159. [CrossRef] [PubMed]

17. Governini, L.; Ponchia, R.; Artini, P.G.; Casarosa, E.; Marzi, I.; Capaldo, A.; Luddi, A.; Piomboni, P. Respiratory Mitochondrial Efficiency and DNA Oxidation in Human Sperm after In Vitro Myo-Inositol Treatment. J. Clin. Med. 2020, 9, 1638. [CrossRef] [PubMed]

18. Alahmar, A.T. Role of Oxidative Stress in Male Infertility: An Updated Review. J. Hum. Reprod. Sci. 2019, 12, 4-18. [CrossRef] [PubMed]

19. Capece, M.; Romeo, G.; Ruffo, A.; Romis, L.; Mordente, S.; Di Lauro, G. A Phytotherapic Approach to Reduce Sperm DNA Fragmentation in Patients with Male Infertility. Urol. J. 2016, 84, 79-82. [CrossRef]

20. Manochantr, S.; Chiamchanya, C.; Sobhon, P. Relationship between chromatin condensation, DNA integrity and quality of ejaculated spermatozoa from infertile men. Andrologia 2011, 44, 187-199. [CrossRef] [PubMed]

21. Agarwal, A.; Majzoub, A.; Baskaran, S.; Panner Selvam, M.K.; Cho, C.L.; Henkel, R.; Finelli, R.; Leisegang, K.; Sengupta, P.; Barbarosie, C.; et al. Sperm DNA Fragmentation: A New Guideline for Clinicians. World J. Mens Health 2020, 38, 412-471. [CrossRef]

22. Asadi, A.; Ghahremani, R.; Abdolmaleki, A.; Rajaei, F. Role of sperm apoptosis and oxidative stress in male infertility: A narrative review. Int. J. Reprod. Biomed. 2021, 19, 493-504. [CrossRef]

23. Perillo, B.; Di Donato, M.; Pezone, A.; Di Zazzo, E.; Giovannelli, P.; Galasso, G.; Castoria, G.; Migliaccio, A. ROS in cancer therapy: The bright side of the moon. Exp. Mol. Med. 2020, 52, 192-203. [CrossRef]

24. Chauvin, T.R.; Griswold, M.D. Characterization of the Expression and Regulation of Genes Necessary for myo-Inositol Biosynthesis and Transport in the Seminiferous Epithelium1. Biol. Reprod. 2004, 70, 744-751. [CrossRef]

25. Rose, A.F.D.; Baldi, M.; Gallo, F.; Rossi, P.; Gattuccio, I.; Marino, A.; Canepa, P.; Mantica, G.; Paraboschi, I.; Gattuccio, F. The management of male infertility: From nutraceuticals to diagnostics. Int. J. Med. Device Adjuv. Treat. 2018, 1, e110.

26. Condorelli, R.A.; La Vignera, S.; Bellanca, S.; Vicari, E.; Calogero, A.E. Myoinositol: Does It Improve Sperm Mitochondrial Function and Sperm Motility? Urology 2012, 79, 1290-1295. [CrossRef]

27. Calogero, A.E.; Gullo, G.; La Vignera, S.; Condorelli, R.A.; Vaiarelli, A. Myoinositol improves sperm parameters and serum reproductive hormones in patients with idiopathic infertility: A prospective double-blind randomized placebo-controlled study. Andrology 2015, 3, 491-495. [CrossRef] [PubMed] 
28. Vazquez-Levin, M.H.; Verón, G.L. Myo-inositol in health and disease: Its impact on semen parameters and male fertility. Andrology 2020, 8, 277-298. [CrossRef] [PubMed]

29. Esposito, S.; Cofini, M.; Rigante, D.; Leonardi, A.; Lucchetti, L.; Cipolla, C.; Lanciotti, L.; Penta, L. Inhibin B in healthy and cryptorchid boys. Ital. J. Pediatr. 2018, 44, 1-7. [CrossRef]

30. Boni, R.; Gallo, A.; Cecchini, S. Kinetic activity, membrane mitochondrial potential, lipid peroxidation, intracellular pH and calcium of frozen/thawed bovine spermatozoa treated with metabolic enhancers. Andrology 2016, 5, 133-145. [CrossRef] [PubMed]

31. Artini, P.G.; Casarosa, E.; Carletti, E.; Monteleone, P.; Di Noia, A.; Di Berardino, O.M. In vitro effect of myo-inositol on sperm motility in normal and oligoasthenospermia patients undergoing in vitro fertilization. Gynecol. Endocrinol. 2016, 33, 109-112. [CrossRef]

32. Brahim, S.F.; Osman, K.; Das, S.; Othman, A.M.; Majid, N.A.; Rahman, M.P.A. A study of the antioxidant effect of alpha lipoic acids on sperm quality. Clinics 2008, 63, 545-550. [CrossRef]

33. Bingham, P.M.; Stuart, S.D.; Zachar, Z. Lipoic acid and lipoic acid analogs in cancer metabolism and chemotherapy. Expert Rev. Clin. Pharmacol. 2014, 7, 837-846. [CrossRef]

34. Ali, Y.F.; Desouky, O.S.; Selim, N.S.; Ereiba, K.M. Assessment of the role of $\alpha$-lipoic acid against the oxidative stress of induced iron overload. J. Radiat. Res. Appl. Sci. 2015, 8, 26-35. [CrossRef]

35. Haghighian, H.K.; Haidari, F.; Mohammadi-Asl, J.; Dadfar, M. Randomized, triple-blind, placebo-controlled clinical trial examining the effects of alpha-lipoic acid supplement on the spermatogram and seminal oxidative stress in infertile men. Fertil. Steril. 2015, 104, 318-324. [CrossRef] [PubMed]

36. Taherian, S.S.; Khayamabed, R.; Tavalaee, M.; Nasr-Esfahani, M.H. Alpha-lipoic acid minimises reactive oxygen species-induced damages during sperm processing. Andrologia 2019, 51, e13314. [CrossRef] [PubMed]

37. Di Tucci, C.; Galati, G.; Mattei, G.; Bonanni, V.; Capri, O.; D’Amelio, R.; Muzii, L.; Benedetti Panici, P. The role of alpha lipoic acid in female and male infertility: A systematic review. Gynecol. Endocrinol. 2021, 37, 497-505. [CrossRef] [PubMed]

38. Barati, E.; Nikzad, H.; Karimian, M. Oxidative stress and male infertility: Current knowledge of pathophysiology and role of antioxidant therapy in disease management. Cell Mol. Life Sci. 2019, 77, 93-113. [CrossRef] [PubMed]

39. Abbasi, B.; Molavi, N.; Tavalaee, M.; Abbasi, H.; Nasr-Esfahani, M.H. Alpha-lipoic acid improves sperm motility in infertile men after varicocelectomy: A triple-blind randomized controlled trial. Reprod. Biomed. Online 2020, 41, 1084-1091. [CrossRef] [PubMed]

40. Asa, E.; Ahmadi, R.; Mahmoodi, M.; Mohammadniya, A. Supplementation of freezing media with alpha lipoic acid preserves the structural and functional characteristics of sperm against cryodamage in infertile men with asthenoteratozoospermia. Cryobiology 2020, 96, 166-174. [CrossRef] [PubMed]

41. Khan, M.S.; Zaman, S.; Sajjad, M.; Shoaib, M.; Gilani, G. Assessment of the level of trace element zinc in seminal plasma of males and evaluation of its role in male infertility. Int. J. Appl. Basic Med. Res. 2011, 1, 93-96. [CrossRef]

42. Razavi, S.R.; Khadivi, F.; Hashemi, F.; Bakhtiari, A. Effect of Zinc on Spermatogenesis and Sperm Chromatin Condensation in Bleomycin, Etoposide, Cisplatin Treated Rats. Cell J. Yakhteh 2019, 20, 521-526.

43. Ishizuka, M.; Ohtsuka, E.; Inoue, A.; Odaka, M.; Ohshima, H.; Tamura, N.; Yoshida, K.; Sako, N.; Baba, T.; Kashiwabara, S.; et al. Abnormal spermatogenesis and male infertility in testicular zinc finger protein Zfp318 -knockout mice. Dev. Growth Differ. 2016, 58, 600-608. [CrossRef]

44. Björndahl, L.; Kvist, U. Human sperm chromatin stabilization: A proposed model including zinc bridges. Mol. Hum. Reprod. 2009, 16, 23-29. [CrossRef]

45. Kothari, R.P.; Chaudhari, A.R. Zinc Levels in Seminal Fluid in Infertile Males and its Relation with Serum Free Testosterone. J. Clin. Diagn. Res. JCDR 2016, 10, CC05-CC08. [CrossRef] [PubMed]

46. Colagar, A.H.; Marzony, E.T.; Chaichi, M.J. Zinc levels in seminal plasma are associated with sperm quality in fertile and infertile men. Nutr. Res. 2009, 29, 82-88. [CrossRef] [PubMed]

47. Alsalman, A.R.S.; Almashhedy, L.A.; Alta'ee, A.H.; Hadwan, M.H. Effect of Zinc Supplementation on Urate Pathway Enzymes in Spermatozoa and Seminal Plasma of Iraqi Asthenozoospermic Patients: A Randomized Controlled Trial. Int. J. Fertil. Steril. 2019, 13, 315-323. [PubMed]

48. Allouche-Fitoussi, D.; Breitbart, H. The Role of Zinc in Male Fertility. Int. J. Mol. Sci. 2020, 21, 7796. [CrossRef]

49. Nematollahi-Mahani, S.N.; Azizollahi, G.H.; Baneshi, M.R.; Safari, Z.; Azizollahi, S. Effect of folic acid and zinc sulphate on endocrine parameters and seminal antioxidant level after varicocelectomy. Andrologia 2014, 46, 240-245. [CrossRef]

50. De Luca, M.N.; Colone, M.; Gambioli, R.; Stringaro, A.; Unfer, V. Oxidative Stress and Male Fertility: Role of Antioxidants and Inositols. Antioxidants 2021, 10, 1283. [CrossRef]

51. Raigani, M.; Yaghmaei, B.; Amirjannti, N.; Lakpour, N.; Akhondi, M.M.; Zeraati, H.; Hajihosseinal, M.; Sadeghi, M.R. The micronutrient supplements, zinc sulphate and folic acid, did not ameliorate sperm functional parameters in oligoasthenoteratozoospermic men. Andrologia 2014, 46, 956-962. [CrossRef]

52. Irani, M.; Amirian, M.; Sadeghi, R.; Le Lez, J.; Roudsari, R.L. The Effect of Folate and Folate Plus Zinc Supplementation on Endocrine Parameters and Sperm Characteristics in Sub-Fertile Men: A Systematic Review and Meta-Analysis. Urol. J. 2017, 14, 4069-4078. [CrossRef] 
53. Salvio, G.; Cutini, M.; Ciarloni, A.; Giovannini, L.; Perrone, M.; Balercia, G. Coenzyme Q10 and Male Infertility: A Systematic Review. Antioxidants 2021, 10, 874. [CrossRef]

54. Lafuente, R.; González-Comadrán, M.; Solà, I.; López, G.; Brassesco, M.; Carreras, R.; Checa, M.A. Coenzyme Q10 and male infertility: A meta-analysis. J. Assist. Reprod. Genet. 2013, 30, 1147-1156. [CrossRef]

55. Fortification methods of coenzyme Q10 in yogurt and its health functionality-A review. Front Biosci. Sch. 2021, 13, 131. [CrossRef] [PubMed]

56. Festa, R.; Giacchi, E.; Raimondo, S.; Tiano, L.; Zuccarelli, P.; Silvestrini, A.; Meucci, E.; Littarru, G.P.; Mancini, A. Coenzyme Q10 supplementation in infertile men with low-grade varicocele: An open, uncontrolled pilot study. Andrologia 2014, 46, 805-807. [CrossRef] [PubMed]

57. Alahmar, A.T.; Calogero, A.E.; Singh, R.; Cannarella, R.; Sengupta, P.; Dutta, S. Coenzyme Q10, oxidative stress, and male infertility: A review. Clin. Exp. Reprod. Med. 2021, 48, 97-104. [CrossRef] [PubMed]

58. Nadjarzadeh, A.; Shidfar, F.; Amirjannati, N.; Vafa, M.; Motevalian, S.A.; Gohari, M.R.; Kakhki, S.A.N.; Akhondi, M.M.; Sadeghi, M.R. Effect of Coenzyme Q10 supplementation on antioxidant enzymes activity and oxidative stress of seminal plasma: A double-blind randomised clinical trial. Andrologia 2013, 46, 177-183. [CrossRef]

59. García-Díaz, E.C.; Gómez-Quiroz, L.E.; Arenas-Ríos, E.; Aragón-Martínez, A.; Ibarra-Arias, J.A.; Retana-Márquez, M.D.S.I Oxidative status in testis and epididymal sperm parameters after acute and chronic stress by cold-water immersion in the adult rat. Syst. Biol. Reprod. Med. 2015, 61, 150-160. [CrossRef]

60. Thakur, A.S.; Littarru, G.P.; Funahashi, I.; Painkara, U.S.; Dange, N.S.; Chauhan, P. Effect of Ubiquinol Therapy on Sperm Parameters and Serum Testosterone Levels in Oligoasthenozoospermic Infertile Men. J. Clin. Diagn. Res. JCDR 2015, 9, BC01-BC03. [CrossRef]

61. Pieczyńska, J.; Grajeta, H. The role of selenium in human conception and pregnancy. J. Trace Elem. Med. Biol. 2015, 29, 31-38. [CrossRef]

62. Mintziori, G.; Mousiolis, A.; Duntas, L.; Goulis, D.G. Evidence for a manifold role of selenium in infertility. Hormones 2019, 19, 55-59. [CrossRef]

63. Foresta, C.; Flohé, L.; Garolla, A.; Roveri, A.; Ursini, F.; Maiorino, M. Male fertility is linked to the selenoprotein phospholipid hydroperoxide glutathione peroxidase. Biol. Reprod. 2002, 67, 967-971. [CrossRef]

64. Michaelis, M.; Gralla, O.; Behrends, T.; Scharpf, M.; Endermann, T.; Rijntjes, E.; Pietschmann, N.; Hollenbach, B.; Schomburg, L. Selenoprotein P in seminal fluid is a novel biomarker of sperm quality. Biochem. Biophys. Res. Commun. 2014, 443, 905-910. [CrossRef]

65. Mistry, H.D.; Pipkin, F.B.; Redman, C.W.; Poston, L. Selenium in reproductive health. Am. J. Obstet. Gynecol. 2012, 206, 21-30. [CrossRef] [PubMed]

66. Talebi, S.; Arab, A.; Sorraya, N. The Association between Dietary Antioxidants and Semen Parameters: A Cross-Sectional Study among Iranian Infertile Men. Biol. Trace Elem. Res. 2021, 5, 1-8. [CrossRef] [PubMed]

67. Mojadadi, A.; Au, A.; Salah, W.; Witting, P.; Ahmad, G. Role for Selenium in Metabolic Homeostasis and Human Reproduction. Nutrients 2021, 13, 3256. [CrossRef] [PubMed]

68. Riaz, M.; Mahmood, Z.; Shahid, M.; Saeed, M.U.Q.; Tahir, I.M.; Shah, S.A.; Munir, N.; El-Ghorab, A. Impact of reactive oxygen species on antioxidant capacity of male reproductive system. Int. J. Immunopathol. Pharmacol. 2015, 29, 421-425. [CrossRef]

69. Cunha, L.M.S.C.P.D.; Teixeira, M.Y.P.; Daltro, A.F.C.S.; Torquato Filho, S.E.; de Assis, R.C.; Celedonio, R.F.; Pires, L.V.; Maia, C.S.C.; Guedes, M.I.F. Unbalance of Se and nutritional status in male infertility. JBRA Assist Reprod. 2021, 25, 202-208. [CrossRef]

70. Ener, K.; Aldemir, M.; Işık, E.; Okulu, E.; Özcan, M.F.; Uğurlu, M.; Tangal, S.; Özayar, A. The impact of vitamin E supplementation on semen parameters and pregnancy rates after varicocelectomy: A randomised controlled study. Andrologia 2016, 48, 829-834. [CrossRef]

71. Rengaraj, D.; Hong, Y.H. Effects of Dietary Vitamin E on Fertility Functions in Poultry Species. Int. J. Mol. Sci. 2015, 16, 9910-9921. [CrossRef]

72. Cyrus, A.; Kabir, A.; Goodarzi, D.; Moghimi, M. The effect of adjuvant vitamin C after varicocele surgery on sperm quality and quantity in infertile men: A double blind placebo controlled clinical trial. Int. Braz J Urol 2015, 41, 230-238. [CrossRef]

73. Hajjar, T.; Soleymani, F.; Vatanchian, M. Protective Effect of Vitamin C and Zinc as an Antioxidant against Chemotherapy-Induced Male Reproductive Toxicity. J. Med. Life 2020, 13, 138-143.

74. Office of Dietary Supplements-Vitamin B12. Available online: https:/ / ods.od.nih.gov/factsheets/VitaminB12-HealthProfessional/ (accessed on 19 December 2020).

75. Banihani, S.A. Vitamin B12 and Semen Quality. Biomolecules 2017, 7, 42. [CrossRef]

76. Hosseinabadi, F.; Jenabi, M.; Ghafarizadeh, A.A.; Yazdanikhah, S. The effect of vitamin B12 supplement on post-thaw motility, viability and DNA damage of human sperm. Andrologia 2020, 52, e13877. [CrossRef] [PubMed]

77. Aoun, A.; Khoury, V.E.; Malakieh, R. Can Nutrition Help in the Treatment of Infertility? Prev. Nutr. Food Sci. 2021, 26, 109-120. [CrossRef] [PubMed]

78. Terai, K.; Horie, S.; Fukuhara, S.; Miyagawa, Y.; Kobayashi, K.; Tsujimura, A. Combination therapy with antioxidants improves total motile sperm counts: A Preliminary Study. Reprod. Med. Biol. 2019, 19, 89-94. [CrossRef]

79. Bisht, S.; Faiq, M.; Tolahunase, M.; Dada, R. Oxidative stress and male infertility. Nat. Rev. Urol. 2017, 14, 470-485. [CrossRef] [PubMed] 
80. Santoro, M.; Aquila, S.; Russo, G. Sperm performance in oligoasthenoteratozoospermic patients is induced by a nutraceuticals mix, containing mainly myo-inositol. Syst. Biol. Reprod. Med. 2020, 67, 50-63. [CrossRef]

81. Scaruffi, P.; Licata, E.; Maccarini, E.; Massarotti, C.; Bovis, F.; Sozzi, F.; Stigliani, S.; Lago, A.D.; Casciano, I.; Rago, R.; et al. Oral Antioxidant Treatment of Men Significantly Improves the Reproductive Outcome of IVF Cycles. J. Clin. Med. 2021, $10,3254$. [CrossRef] [PubMed]

82. Steiner, A.Z.; Hansen, K.R.; Barnhart, K.T.; Cedars, M.I.; Legro, R.S.; Diamond, M.P.; Krawetz, S.A.; Usadi, R.; Baker, V.L.; Coward, R.M.; et al. The Effect of Antioxidants on Male Factor Infertility: The MOXI Randomized Clinical Trial. Fertil. Steril. 2020, 113, 552-560.e3. [CrossRef]

83. Salas-Huetos, A.; James, E.R.; Aston, K.I.; Jenkins, T.G.; Carrell, D.T. Diet and sperm quality: Nutrients, foods and dietary patterns. Reprod. Biol. 2019, 19, 219-224. [CrossRef] [PubMed]

84. Salas-Huetos, A.; Bulló, M.; Salas-Salvadó, J. Dietary patterns, foods and nutrients in male fertility parameters and fecundability: A systematic review of observational studies. Hum. Reprod. Update 2017, 23, 371-389. [CrossRef] [PubMed]

85. Ozer, C. Antioxidant Treatment of Increased Sperm DNA Fragmentation: Complex Combinations Are Not More Successful. Arch. Ital. Urol. E Androl. 2020, 92, 4. [CrossRef]

86. Scroppo, F.I.; Costantini, E.; Zucchi, A.; Illiano, E.; Trama, F.; Brancorsini, S.; Crocetto, F.; Gismondo, M.R.; Dehò, F.; Mercuriali, A.; et al. COVID-19 disease in clinical setting: Impact on gonadal function, transmission risk, and sperm quality in young males. J. Basic Clin. Physiol. Pharmacol. 2021. [CrossRef] [PubMed] 